\title{
LA SEMEJANZA CON LA LENGUA MATERNA: TROPIEZOS PARA EL APRENDIZAJE DEL ESPAÑOL
}

\author{
Nair Nodoca Takeuchi \\ Universidade Federal do Paraná
}

\begin{abstract}
RESUMEN
Uno de los grandes tropiezos en la fase inicial del aprendizaje de español por estudiantes brasileños es la grande semejanza de su lengua materna con la lengua española. Ante un pequeño percenta. je de palabras distintas, hay una multitud de vocablos comunes a las dos lenguas, muchas idénticas, otras semejantes, pero no iguales, y que confunden a los alumnos. El profesor necesita sacar provecho de la semejanza existente entre esas dos lenguas.
\end{abstract}

Por lo general, las expectativas de estudiantes brasileños que se matriculan en cursos de lengua española son de que, como la lengua es muy semejante con su lengua materna, dentro de poco tiempo la están dominando razonablemente bien. Normalmente vienen convictos de que el español es fácil. Y lo es. Sin embargo, a medida que los estudiantes tienen un contacto más frecuente $y$ sistemático con la lengua, se dan cuenta que la semejanza que creían ser tan grande, es relativa, aunque las lenguas portuguesa y española scan las que presentan mayor transparencia linguística entre las lenguas románicas. "Son mellizas, aunque no siamesas", según Leo Gibson Ribeiro.'

Nuestra experiencia de diez años en la enseñanza de español a universitarios brasileños demostraron :jue uno de los grandes tropiezos en la producción oral y escrita de esos estudiantes es justo la grande semejanza que hay entre las dos lenguas. La expectativa y el

${ }^{1}$ RIBEIRO, L G. Portugués al instante. Lifo en español, 31 (6) : 3, mar. 1968.

Letras. Curitiba (33) 181-185 - 1984 - UFPR 
entusiasmo iniciales son frenados cuando encuentran dificultades de reproducir sonidos de la lengua española en vocablos que les son familiares, como jardín, noche, español, América, rio, región.

La estructura de la lengua, por lo general, no ofrece muchas dificultades a los aprendices. Pero la semejanza lexical es el grande tropiezo. Ellos se ven ante un pequeño percentaje de palabras distintas al portugués $y$ una multitud de vocablos comunes a las dos lenguas. Además de eso, dentro de esa mayoría de palabras comunes, encuentran las que son idénticas a su lengua materna, como alimento, minimo, parar, otras que les son familiares, pero de distinta pronunciación o forma, como casa, jardin, Jespués, alguien, polvo, árbol, además de otras con la misma forma y distinta significación, como rato, exquisito y largo.

Es reconocido por los linguistas y sicólogos que el aprendizaje de lenguas extranjeras es más complejo para adultos que para niños, porque éstos son capaces de asimilar la nueva lengua de modo más intuitivo e imitativo. Ya los adultos lanzan mano del razonamiento $y$, consciente o incoscientemente, buscan explicaciones a los fenómenos linju ísticos.

En la búsqueda de la regla de diptongación de e y o tónicos, por ejemplo, los estudiantes encuentran palabras como hierro, pensamiento, tiempo, puerta, fuerza, al lado de otras como cerro, jepartamento, forma, coca, o sea, sin diptongación. Esto puede llevarlos a producir la frase "Quiero un pueco de cueca.", en vez de "Quiero un poco de coca".

En sus estrategias para asimilar da lengua española por medio de reglas de generalización se encuentran ante varios procesos fonológicos distintos para un mismo fonema portugués, como hemos visto. También en el fonema $/ \lambda /$, por ejemplo:

$$
/ x / \rightarrow\left\{\begin{array}{l}
/ x / \\
/ \lambda /
\end{array}\right\} \quad \begin{aligned}
& : \text { :inujar, hijo, ojos, mejor } \\
& : \text { Jatalla, falla, caballos }
\end{aligned}
$$

o, al revés, varios fonemas portugueses que convergen a uno solo en español, como:

$$
/ \lambda /-\left\{\begin{array}{l}
/ \mathrm{s} / \\
/ 1 / \\
/ \mathrm{pl} / \\
/ \mathrm{pr} /
\end{array}\right\} \begin{aligned}
& \text { : chave, chuva - Ilave, lluvia } \\
& \text { : ela, levar - ella, llevar } \\
& \text { : plano - llano } \\
& \text { : pranto - Ilanto }
\end{aligned}
$$

Otra regla que los estudiantes buscan establecer es la grafía de palabras con b y v. Como se trata de la representación gráfica de un mismo sonido, $y$ en analogia con libro, haber, caballo, ocurren llober, imbitar, grabe. Otro tropiezo de escritura se presenta también cuando la palabra es pronunciada igual al portugués y tiene grafía distinta, como 
profesor, pasar y zapato, cabeza (para quienes sesean), o al revés, que se escribe igual $y$ se pronuncia de forma distinta, como casa, gente, jardín, cómodo.

La grande semejanza con la lengua materna les propicia a los estudiantes asociaciones nefastas como las que acabamos de ver. Como, por otra parte, el adulto tiene mayor senso de autocrítica que el niño, en la perspectiva de la posibilidad del error, prefiere no exponerse ante sus compañeros de clase.

Sin embargo, el aspecto positivo de la semejanza linguística entre el portugués y el español está en que el estudiante de español lleva una ventaja muy grande en relación al alumno de lenguas muy distintas como el japonés, el ruso o mismo el inglés. El esfuerzo dispendido en el aprendizaje del vocabulario es reducido, frente al esfuerzo del estudian te de otras lenguas.

Por otra parte, paradojicamente, esta misma ventaja puede provocar una fase de incertidumbre. Son tantas las palabras idénticas a su lengua materna y otras tantas semejantes pero no iguales! Se nos parece que la relativa identidad lingu istica de las dos lenguas hace que los estudiantes se monitoren demasiado, hasta eviten exponerse a la posibilidad del error. En la investigación llevada a cabo en UNICAMP por Maria Rita M. Figueiredo y Silvana M. Serrani se observó, entre otras cosas que, de los cuatro estudiantes de español testados en libre conversación entre ellos, tres eran del tipo de usuario excesivo del monitor, en cuanto que de los dos estudiantes de alemán, uno de ellos pertenecía a este tipo ${ }^{2}$. No cabe dudas que la muestra es muy restringida para hacer generalizaciones, y otras variables deben haber influido en los resultados. Pero nuestra experiencia nos lleva a creer que esa monitoración es causada, principalmente por la inseguridad con relación a la "engañosa" transparencia linguistica. Lo desconcertante para los aprendices es que en la lectura de textos o al escuchar la lengua española, reconocen y entienden las palabras sin dificultad. El problema está en el momento de comunicarse ya oralmente ya por escrito.

Sin duda, cabe al profesor evitar el exceso de monitoración de los alumnos, y sacar provecho de la semejanza entre el español y el portugués, conduciendo la enseñanza de manera a proporcionar confianza y seguridad en la utilización de la lengua que los etudiantes están aprendiendo.

En un curso de lengua española para brasileños es necesario que los alumnos sean expuestos a la lengua española de todas formas, con gran variedad $y$ cantidad de textos orales $y$ escritos. De igual forma

2FIGUEIREDO, M. R. M. \& SERRANI. S. M. Lingua alvo em uso no ensino formal da segunda lingua. Trabalhos em Lingülstica Aplicada, 1 : 133-51, maio 1983.

Letras, Curitiba (33) 181-185 - 1984 - UFPA 
deben ser estimulados a que utilicen lo más posible la lengua española para comunicarse con sus compañeros de clase, con el professor y otros hablantes de lengua castellana. El mayor énfasis al vocabulario debe ser observado, principalmente en la fase inicial del curso, para estimular el habla y rechazar la incertidumbre e inseguridad que agobia a los estudiantes.

Los profesores de la UNICAMP que dan clases de portugués a hablantes extranjeros llegaron a la conclusión que el curso de portugués a hispanohablantes debe ser distinto de los cursos para los demás extranjeros, destacando que no hay que tener un control muy rígido con las estructuras y el vocabulario. Y que debe sí, haber más cuidado en el análisis de los aspectos lexicales contrastantes entre las dos lenguas, como las convergencias semánticas, $y$ de los problemas específicos, como el uso de la preposición. ${ }^{3}$

Estamos de acuerdo, en parte, con esta conclusión, y lo mismo puede ser aplicado en el curso de lengua española para brasileños. Pero señalamos que al dar más énfasis al léxico que a la estructuras de la lengua, los alumnos deben ser llevados a percibir, no solo los aspectos contrastantes, pero también las identidades, ya sean semánticas, ortográficas o fónicas, una vez que hay más semejanza que contraste lexical entre ambas lenguas. De esta forma, a la vez de tropiezos, los alumnos encontrarán, en la semejanza con el lexicón portugués, instrumentos facilitadores del aprendizaje de la lengua española.

"Adaptación del trabajo presentado al curso de "Língua e Habilidades de Estudo", - PUC/ SP, y presentado en el II Seminario de Estudios Hispánicos, en octubre de 1983, patrocinado por la Associacão de Professores de Espanhol do Estado do Rio de Janeiro, que publicará el resumen.

\section{RESUMO}

Um dos grandes tropeços na fase inicial da aprendizagem de espanhol por estudantes brasileiros é a grande semelhança de sua língua materna com a lingua espanhola. Diante de uma pequena percentagem de palavras diferentes, há uma infinidade de vocábulos comuns às duas linguas, muitas idēnticas, outras semelhantes, mas não iguais, e que confundem os alunos. O professor necessita tirar proveito da semelhança existente entre essas duas linguas.

${ }^{3}$ LOMBELLO, L C.; EL.DASH, L. G.; BALEEIRO, M. A. Subsidio para a elaboraçäo de material didático para falantes de espanhol. Trabalhos em Lingüistica Aplicada, 1 : 117.32. maio 1983. 


\section{REFERÊNCIAS BIBLIOGRÁFICAS}

1 FIGUEIREDO, M. R. M. \& SERRANI, S. M. Língua-alvo em uso no ensino formal da segunda lingua. Trabalhos em Lingüistica Aplicada, 1 : 133.51, maio 1983.

2 LOMBELLO, L. C.; EL-DASH, L. G.; BALEEIRO, M. A. Subsídio para a elaboração de material didático para falantes de espanhol. Trabalhos em Lingüística Aplicada, 1: 117-32, maio 1983.

3 RIBEIRO, L. G. Portugués al instante. Life en Español, 31 (6): 3, mar. 1968. 